\title{
Psychological and social consequences of non-invasive prenatal testing (NIPT): a scoping review
}

\author{
Valérie Labonté ${ }^{*}$ (D), Dima Alsaid ${ }^{1}$ (D), Britta Lang ${ }^{2}$ (D) and Joerg J. Meerpohl' (D)
}

\begin{abstract}
Background: Genomics-based noninvasive prenatal tests (NIPT) allow screening for chromosomal anomalies such as Down syndrome (trisomy 21). The technique uses cell-free fetal DNA (cffDNA) that circulates in the maternal blood and is detectable from 5 weeks of gestation onwards. Parents who choose to undergo this relatively new test (introduced in 2011) might be aware of its positive features (i.e. clinical safety and ease of use); however, they might be less aware of the required decisions and accompanying internal conflicts following a potential positive test result. To show the evidence on psychological and social consequences of the use of NIPT, we conducted a scoping review.
\end{abstract}

Methods: We systematically searched four electronic databases (MEDLINE (Ovid), Cochrane Library (Wiley), CINAHL (EBSCO) and PsychINFO (EBSCO)) for studies that investigated the psychological or social consequences of the use of NIPT by pregnant women or expecting parents. The search was limited to studies published between 2011 and August 8, 2018. We identified 2488 studies and, after removal of duplicates, screened 2007 titles and abstracts, and then assessed 99 articles in full text (both screenings were done independently in duplicate). We included 7 studies in our analysis.

Results: Five studies assessed anxiety, psychological distress and/or decisional regret among women with validated psychological tests like the Spielberger State Trait-Anxiety Inventory (STAI), the Pregnancy-Related Anxiety Questionnaire-Revised (PRAQ-R), the Kessler Psychological Distress Scale (K6) or the Decisional Regret Scale (DRS). Two studies assessed women's experiences with and feelings after NIPT in interviews or focus groups. The included studies were heterogeneous in location, study setting, inclusion criteria, outcome assessment, and other characteristics.

Conclusions: Only few studies on psychological consequences of NIPT have been identified. The studies assessed only short-term psychological consequences of NIPT at baseline and/or after receiving the results or after giving birth. Studies show that short term anxiety decreased when women received negative NIPT results and that decisional regret was generally low. We could not identify studies on long term consequences of NIPT, as well as studies on women's partners' short and long term outcomes, nor on social consequences of NIPT.

Keywords: Non-invasive prenatal testing, NIPT, Cell-free fetal DNA, cffDNA, Pregnancy, Down syndrome, Trisomy, Anxiety

\footnotetext{
* Correspondence: labonte@ifem.uni-freiburg.de

${ }^{1}$ Institute for Evidence in Medicine, Medical Center - University of Freiburg, Faculty of Medicine, University of Freiburg, Breisacherstr. 153, 79110 Freiburg, Germany

Full list of author information is available at the end of the article
}

(c) The Author(s). 2019 Open Access This article is distributed under the terms of the Creative Commons Attribution 4.0 International License (http://creativecommons.org/licenses/by/4.0/), which permits unrestricted use, distribution, and reproduction in any medium, provided you give appropriate credit to the original author(s) and the source, provide a link to the Creative Commons license, and indicate if changes were made. The Creative Commons Public Domain Dedication waiver (http://creativecommons.org/publicdomain/zero/1.0/) applies to the data made available in this article, unless otherwise stated. 


\section{Background}

\section{Background of the study}

Since the early 2010s, genomics-based noninvasive prenatal tests (NIPT) based on a blood sample from the pregnant women are offered in antenatal care to expecting parents who have a risk for certain chromosomal anomalies. The available NIPTs usually screen for all of the following seven chromosomal aneuploidies or for a subset of them: Down syndrome (trisomy 21), Edward syndrome (trisomy 18), Patau syndrome (trisomy 13), Turner syndrome $(45, \mathrm{X})$, Klinefelter syndrome (47, $\mathrm{XXY})$, Triple $\mathrm{X}$ syndrome $(47, \mathrm{XXX})$ and Jacobs syndrome $(47, \mathrm{XYY})[1]$.

The conditions caused by these aneuploidies vary considerably in severity and manifestations: Trisomy 21 is the most frequent aneuploidy in children that are born alive and causes mild to severe intellectual disability and several morphological features as well as possibly other medical conditions, such as heart disease. Some individuals can live independently as adults, others need substantial support and care [2]. Of children affected with trisomy 18 or 13 most die before birth or shortly after birth. The other syndromes that NIPT can screen for are aneuploidies of the sex chromosomes X or Y; generally, these have less severe health consequences for the persons affected. Examples in this background section will focus on trisomy 21 , not only because it is the most frequent, but also because most expecting parents are familiar with it [3].

To analyze the fetal genome, NIPT uses cell-free fetal DNA (cffDNA) that circulates in the maternal blood and is detectable in maternal plasma from 5 weeks of gestation [1]. As NIPT is a screening test and not a diagnostic test, it only provides information about the possibility of having an affected fetus. The quality of tests is expressed as sensitivity (percentage of affected fetuses that are correctly identified) and specificity (percentage of nonaffected fetuses that are correctly identified). In a metaanalysis, Badeau et al. reported a high accuracy of NIPT for the detection of trisomy 21, trisomy 18, and trisomy 13 in women at a high risk for fetal aneuploidy (sensitivities (95\% confidence interval) from 95.8\% (86.1 - 98.9\%) to $99.7 \%$ (98.0 - 100\%); specificities above $99 \%$; almost all studies had a high risk of bias) [1].

Its high specificity for at least trisomy 21 sufficiently reassures many women who received a negative NIPT test result, so that there is no need for invasive diagnostic testing for confirmation of absence of these common chromosomal anomalies [4]. Women with a positive NIPT test result still do require an invasive test (e.g., karyotyping by chorionic villus sampling, CVS) for definitive confirmation because of the possibility of a false positive result. The likelihood of a false positive result for trisomy 21 for a 40 year old woman for example is $7.9 \%$ (given a prevalence of trisomy 21 of 1:85 [5]).

As there is no cure for chromosomal anomalies, continuation or termination of the pregnancy are the two options for expecting parents after discovery. An early detection of a chromosomal anomaly has certain advantages, such as more time for decision making, privacy (as fewer people are aware of the pregnancy), better management of pregnancy and birth, and safer methods of termination. On the other hand, 15\% of trisomy 21 pregnancies are affected by spontaneous abortion at the end of the first or beginning of the second trimester (between 11 and 16 weeks), so that an affected fetus might naturally have been lost only shortly after discovery [4].

\section{Why this study should be made}

NIPT is and has been seen as a breakthrough in prenatal screening for chromosomal anomalies because of its clinical safety and ease of use. Expecting parents who decide to undergo this relatively new test might only be aware of its positive features (i.e. no physical risk for the pregnant women or the baby) but they might be less aware of the possible upcoming decisions and internal conflicts affecting their pregnancy.

Green et al. conducted a systematic review (health technology assessment (HTA) report) on psychosocial aspects of genetic screening of pregnant women and newborns in 2004, before NIPT was introduced. They found that there was lack of evidence for a beneficial or reassuring effect of receiving a negative screening result; however, anxiety was raised in women receiving positive screening results. Up to $30 \%$ of women receiving a positive screening result in pregnancy expressed regret about their screening decision afterwards [6].

Bryant found, that undergoing NIPT as well as invasive testing, is often associated with high levels of anxiety (because of the fear of a positive result) [7]. Hodgson states that "parents [receiving a prenatal diagnosis of chromosomal anomaly] frequently experience acute grief responses and strong emotions of guilt, anger, and loss" [8]. As stress during pregnancy could possibly have negative consequences on the fetus (e.g. low birth weight) [9], clinicians, health policy makers, pregnant women, and their partners should be aware of the possibility of such consequences in advance.

Expecting parents or pregnant women in particular might perceive pressure to undergo NIPT, either from their social environment or from medical professionals. The decision against NIPT might even be seen as irresponsible, especially when women who deny NIPT, also deny invasive testing due to the risk of miscarriage [10].

Moreover, the marketing of the commercially available NIPT might simplify or even oversimplify its benefits. Advertisements and media coverage influence the 
perceived relevance of potential consumers who do not have an elevated risk for aneuploidies. Press articles on NIPT in the UK from a sample taken in 2014 showed a tendency to hype the benefits of NIPT [11].

Before undergoing such a test and coping with potentially negative results, psychological or social consequences of NIPT should be known. This aspect might become relevant on a public health scale and not only for subpopulations.

For informed choices on NIPT and possible consequences, obstetricians and gynecologists should be aware of the possible psychological and social consequences of NIPT for expecting parents and embed them in their deliberations. To our knowledge, no scoping or systematic review which investigates psychological and social consequences on NIPT has yet been published. While the diagnostic test accuracy and clinical utility of NIPT has been shown in systematic reviews (as for example in [1]), less is known on psychological and social consequences of its application. Therefore, we decided to conduct a scoping review on the psychological and social consequences of NIPT including a systematic search for studies assessing consequences of the use of NIPT.

\section{Methods}

We chose a scoping review as a research format. This type of knowledge synthesis is suitable to identify existing evidence and research gaps in an emerging research area $[12,13]$. In contrast to other evidence synthesis formats (as systematic reviews, for example), the quality of studies to be included in a scoping review is usually not assessed.

We based our method on the five steps of the original framework from Arksey and O'Malley [14] and a refinement by Levac et al. [15].

\section{Step 1: identifying the research question}

We identified the research question in the context of a research project about the quality of the media coverage on NIPT in Germany: What is the evidence on psychological and social consequences of the use of NIPT?

\section{Step 2: identifying relevant studies}

We developed a systematic literature search strategy (Additional file 1) with support of an information specialist (EM) [see Additional file 1]. We used a modified PICO-format to build our strategy around the aspects population (e.g. pregnant women, parents), intervention (e.g. NIPT, prenatal diagnosis/screening) and - to limit our search and thus receive a manageable number of results - outcome (e.g. maternal behavior, anxiety, social support). During testing of our search strategy, we omitted search terms that appeared to be relevant but did not add any relevant citations to the search result. Therefore, the search terms for different databases vary slightly.

We ran our searches on August 8, 2018, in the electronic databases MEDLINE (Ovid), Cochrane Library (Wiley), CINAHL (EBSCO) and PsychINFO (EBSCO). The searches were limited to studies published from 2011 onwards because NIPT was only introduced in 2011 [16]. Duplicates were removed using the algorithm of Bramer et al. [17].

\section{Step 3: study selection}

We screened all unique references in two steps (title \& abstracts, then full texts) by two reviewers (VL, DA) independently in the Covidence web application [18].

Inclusion criteria for both screening steps were:

- Population: pregnant women, parents

- Intervention: NIPT, cell-free fetal DNA (cffDNA)

- Outcome: psychological and social outcomes after NIPT

Study selection was not limited to a certain type of study, or by language.

Exclusion criteria: studies that did not match the above mentioned criteria. For example, studies on the decision-making processes or studies that were conducted before the introduction of NIPT.

\section{Step 4: charting the data}

We extracted data of included studies in duplicate using a piloted, dedicated data abstraction form and summarized data narratively and in tables. Extracted data consisted of bibliographic information, study and women's characteristics, outcomes relevant to our study question and additional data such as conflicts of interest.

\section{Step 5: collating, summarizing and reporting the results} General characteristics on the studies are shown in Table 1 . We collated details and results of the included studies according to the types of outcomes that had been assessed in the studies (i.e. results from psychological tests (Table 2), women's experiences (Table 3), and quotes from interviews or focus groups (Table 4). We also analyzed and summarized the results narratively.

As the authors of the included studies used different expressions to describe NIPT results, we harmonized the use of the expressions throughout our results section and in the tables, as follows: 'negative NIPT result' includes e.g. 'normal' or 'low-risk' NIPT result, 'positive NIPT result' includes e.g. 'abnormal' or 'high-risk' NIPT result. 


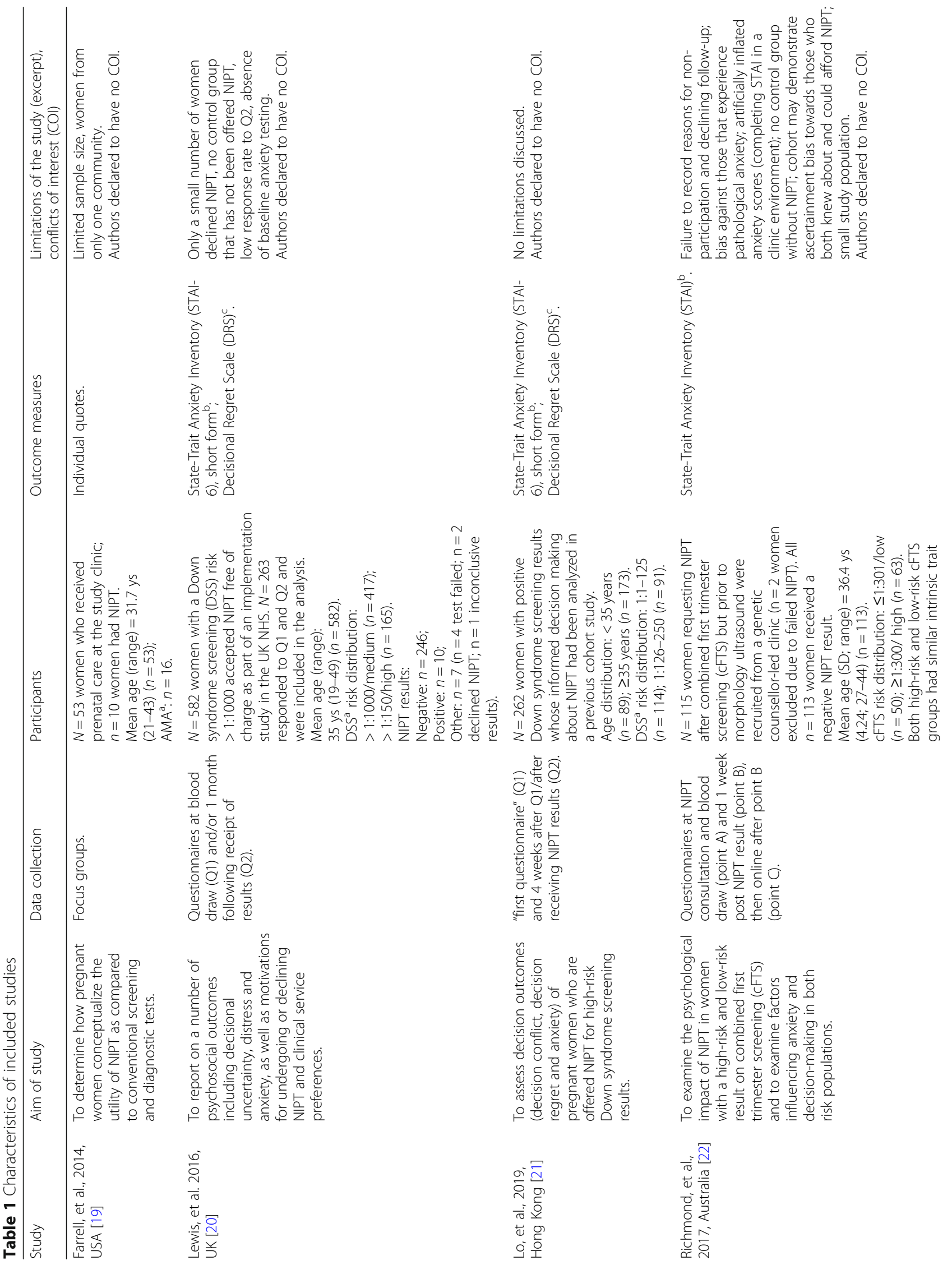




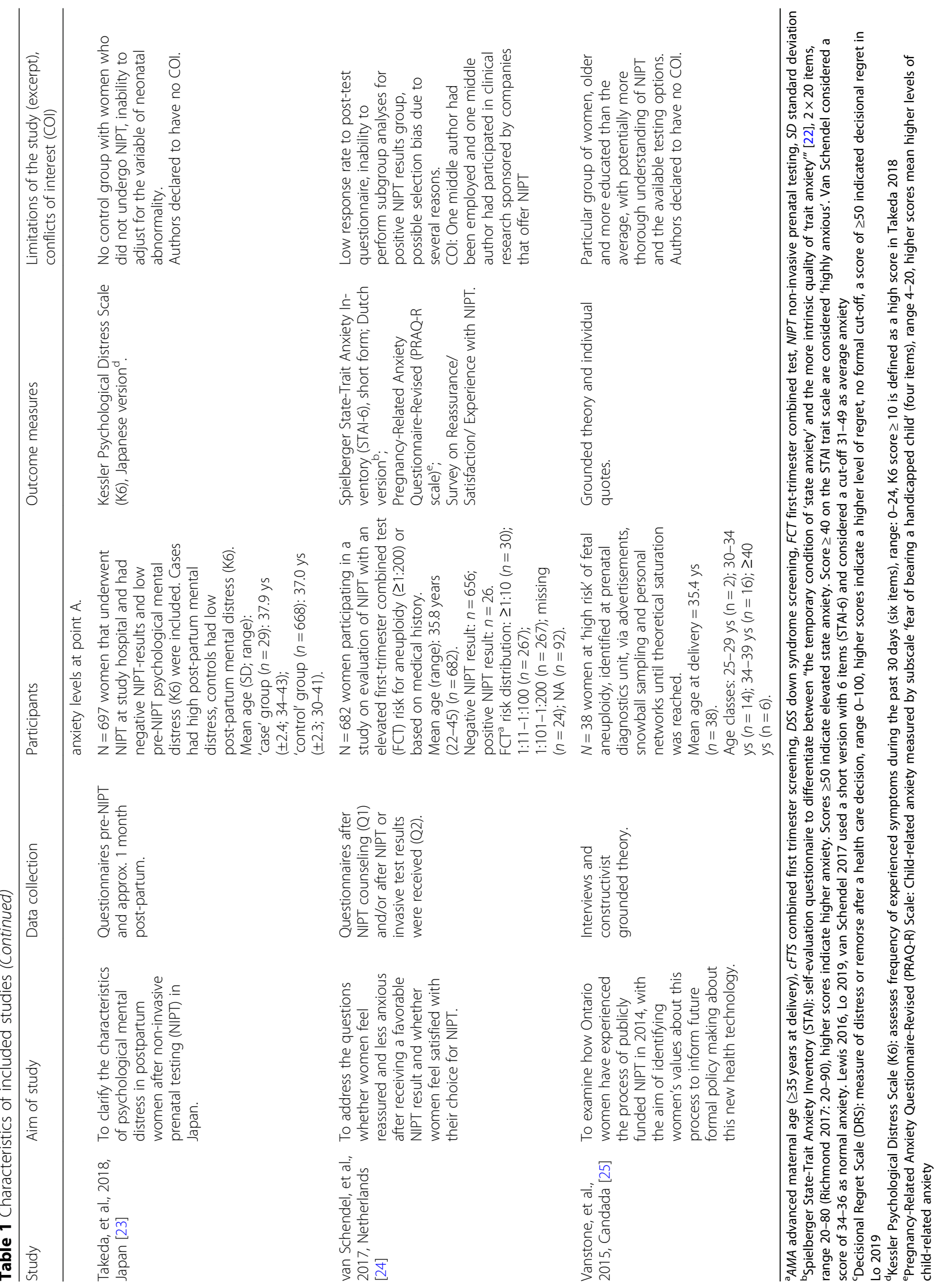




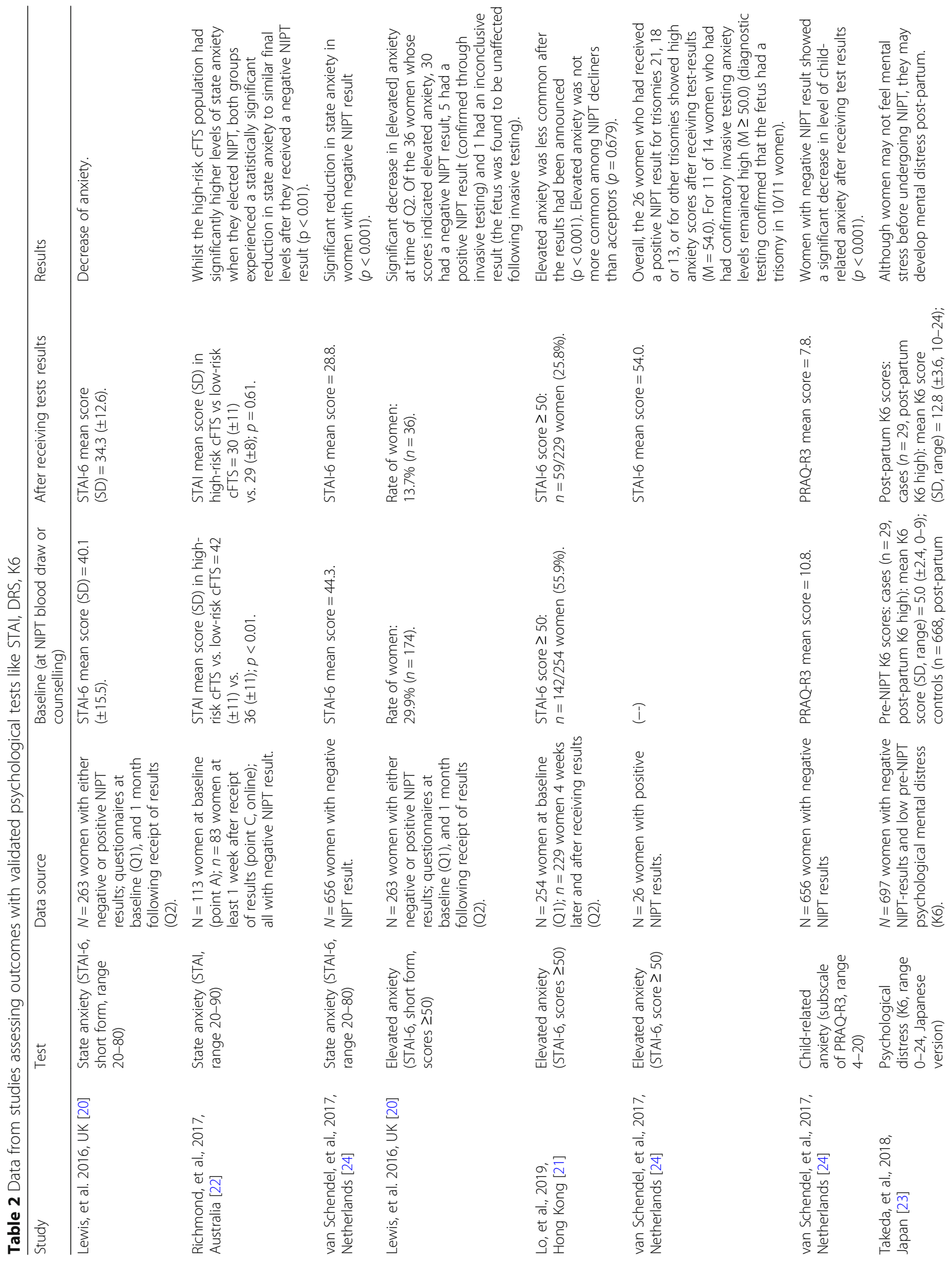




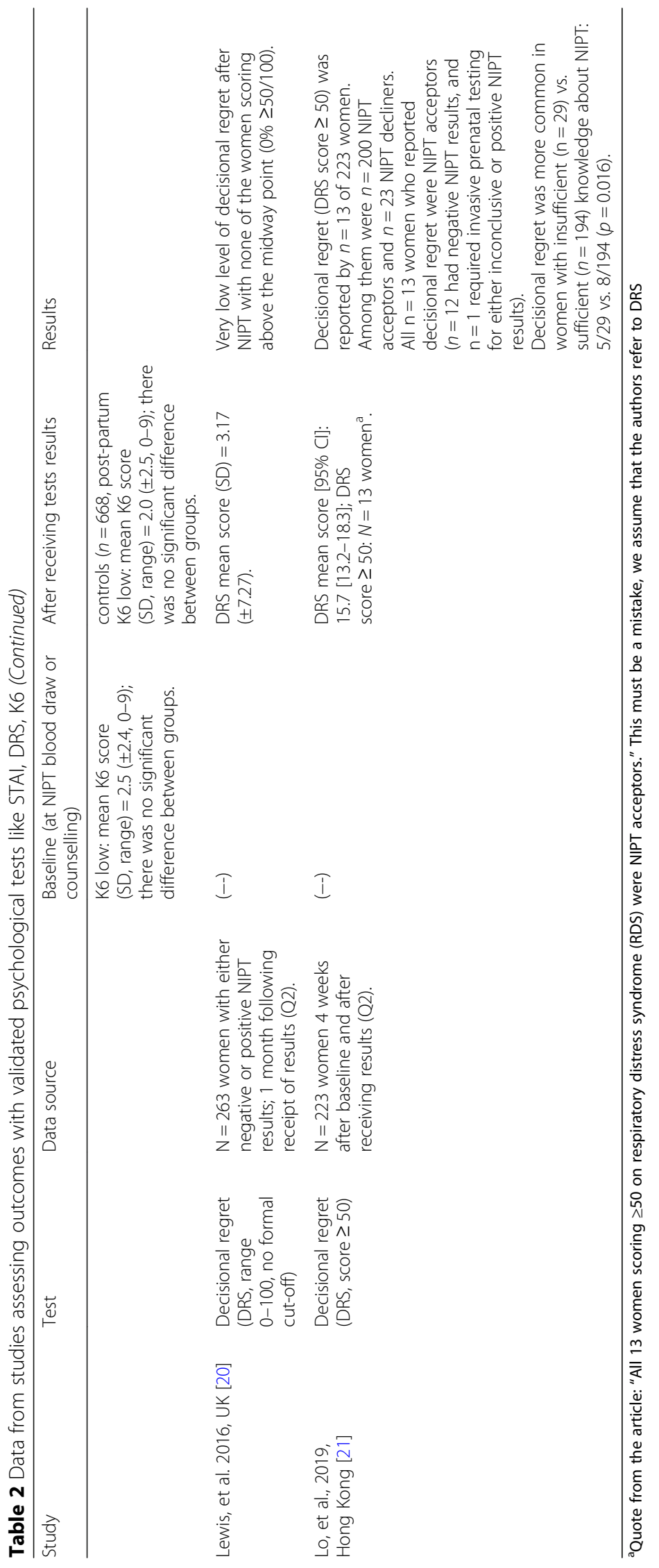


Table 3 Data from questionnaires assessing experiences with NIPT (van Schendel et al., 2017, Netherlands)

\begin{tabular}{|c|c|c|}
\hline Question & Data source & Responses and/or results \\
\hline $\begin{array}{l}\text { Reassurance: } \\
\text { 'I felt reassured by the test-result' (Scale: not at all } \\
\text { applicable (1) - very much applicable (5)) }\end{array}$ & $\mathrm{N}=656$ women with negative NIPT results. & $\begin{array}{l}\text { - } 2.4 \% \text { not at all applicable } \\
\text { - } 0.9 \% \text { hardly applicable } \\
\text { - } 15.7 . \% \text { somewhat applicable } \\
\text { - } 80.9 \% \text { very much applicable }\end{array}$ \\
\hline $\begin{array}{l}\text { Confidence: } \\
\text { 'I am confident that the test-result is correct' } \\
\text { (Scale: not at all applicable (1) - very much } \\
\text { applicable (5)) }\end{array}$ & $\mathrm{N}=656$ women with negative NIPT results. & $\begin{array}{l}\text { - } 0.2 \% \text { not at all applicable } \\
\text { - } 0.6 \% \text { hardly applicable } \\
\text { - } 18.3 \% \text { somewhat applicable } \\
\text { - } 80.9 \% \text { very much applicable }\end{array}$ \\
\hline $\begin{array}{l}\text { Certainty: } \\
\text { The test result offers me sufficient certainty } \\
\text { whether my child has a disorder' (Scale: not } \\
\text { at all applicable (1) - very much applicable (5)) }\end{array}$ & $N=656$ women with negative NIPT results. & $\begin{array}{l}\text { - } 0.3 \% \text { not at all applicable } \\
\text { - } 1.4 \% \text { hardly applicable } \\
\text { - } 34.0 \% \text { somewhat applicable } \\
\text { - } 64.3 \% \text { very much applicable }\end{array}$ \\
\hline $\begin{array}{l}\text { Satisfaction with NIPT: } \\
\text { (Scale: not at all applicable (1) - very much } \\
\text { applicable (4) }\end{array}$ & N = 656 women with negative NIPT results. & $\begin{array}{l}2.4 \%(n=16) \text { women would rather } \\
\text { have had invasive testing than NIPT } \\
\text { (shorter waiting time, more accurate } \\
\text { results) }\end{array}$ \\
\hline $\begin{array}{l}\text { Satisfaction with NIPT: } \\
\text { (Scale: not at all applicable (1) - very much } \\
\text { applicable (4) }\end{array}$ & $N=682$ women with negative or positive NIPT results. & $\begin{array}{l}97.5 \% \text { had no regret on NIPT; } 28.6 \% \\
\text { would have preferred to receive } \\
\text { results earlier. }\end{array}$ \\
\hline $\begin{array}{l}\text { Experience with test offer and procedure. } \\
\text { (Scale: completely disagree (1) - completely } \\
\text { agree (5), compressed to 3-point scale) }\end{array}$ & $\mathrm{N}=682$ women with negative or positive NIPT results. & $\begin{array}{l}96.1 \% \text { of participating women have } \\
\text { been glad to have been offered NIPT, } \\
85.9 \% \text { had had sufficient time to } \\
\text { reflect on their choice. }\end{array}$ \\
\hline $\begin{array}{l}\text { Waiting time for test results. (Scale: way too } \\
\text { long (1) - way too short (5)) }\end{array}$ & N = 682 women with negative or positive NIPT results. & $\begin{array}{l}\text { Reported waiting time until NIPT result: } \\
\text { mean }=15 \text { days (range } 5-32 \text { days). } \\
\text { Waiting time was considered (much) } \\
\text { too long by } 68.5 \% \text { of women, for } 31.5 \% \\
\text { it was neither too long nor too short. } \\
\text { A waiting time of } \leq 10 \text { days was } \\
\text { acceptable for most women, longer } \\
\text { was considered too long by the } \\
\text { majority of women. }\end{array}$ \\
\hline
\end{tabular}

\section{Results}

We identified a total of 2488 records. After removal of duplicates, 2007 titles and abstracts were screened; subsequently, the full-texts of 99 articles were assessed. 7 studies have been included (see PRISMA flow chart in Fig. 1).

\section{Characteristics of the included studies and women therein}

Five studies assessed anxiety, psychological distress and/ or decisional regret with validated psychological tests like the Spielberger State-Trait Anxiety Inventory (STAI or short form STAI-6), the Pregnancy-Related Anxiety Questionnaire-Revised (PRAQ-R), the Kessler Psychological Distress Scale (K6) or the Decisional Regret Scale (DRS) [20-24]. Questionnaires usually were administered at baseline (i.e. at NIPT blood draw or counseling) and after receiving NIPT results. One study conducted a survey on satisfaction and experience with NIPT [24]. Two studies assessed women's experiences with and feelings after NIPT in interviews or focus groups [19, 25]. For more details, see Table 1.

The studies were published between 2014 and 2018 with data being assessed from 2013 until 2016 on. Two studies each were conducted in Europe [20, 24], Asia $[21,23]$ or North America $[19,25]$, one study was from Australia [22]. Four studies were single center studies $[19,22,23,25]$, three studies were multi-centric $[20,21$, 24]. Five studies assessed outcomes with selfadministered questionnaires [20-24], one study conducted interviews [25], and one study worked with focus groups [19].

The number of participating women in the studies assessing outcomes with questionnaires ranged from 115 to 697; in the two studies that conducted interviews or focus groups, 38 and 53 women participated $[19,25]$.

Five studies reported a mean age of participating women $[19,20,22,23]$ : The mean age of all included women over those five studies was 35.9 years, with the youngest and oldest age of 19 and 49 (extremities of range reported; standard deviation not reported in all studies). One study only reported the mean age of women when giving birth of 35.4 years and age classes in steps of 5 years $(25-29 ; 30-34 ; 34-39 ; \geq 40)$ [25], the other study reported women's age in two groups $(<35$; 235 ) [21], with the majority of women in those two studies being 35 years or older. 


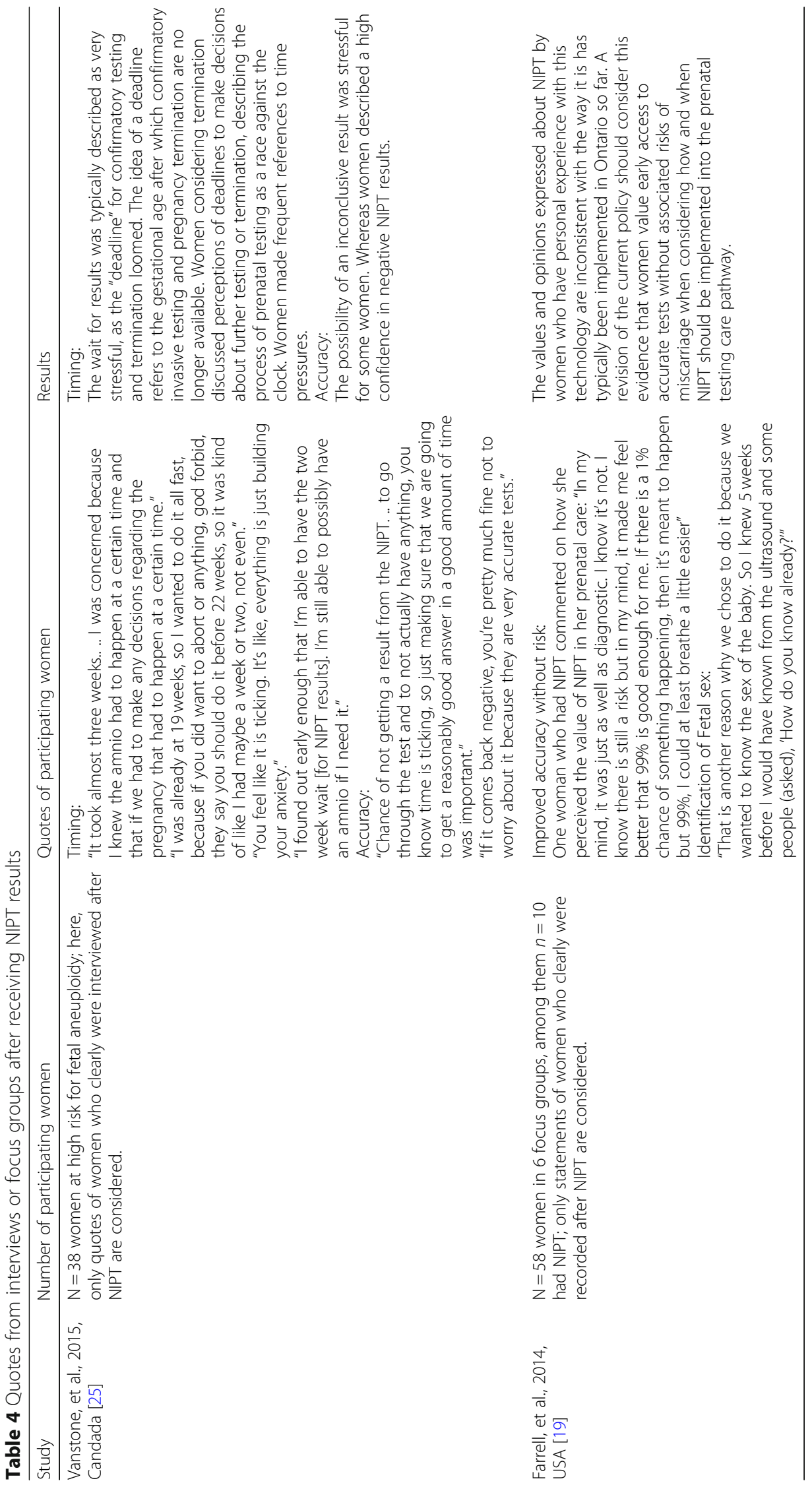




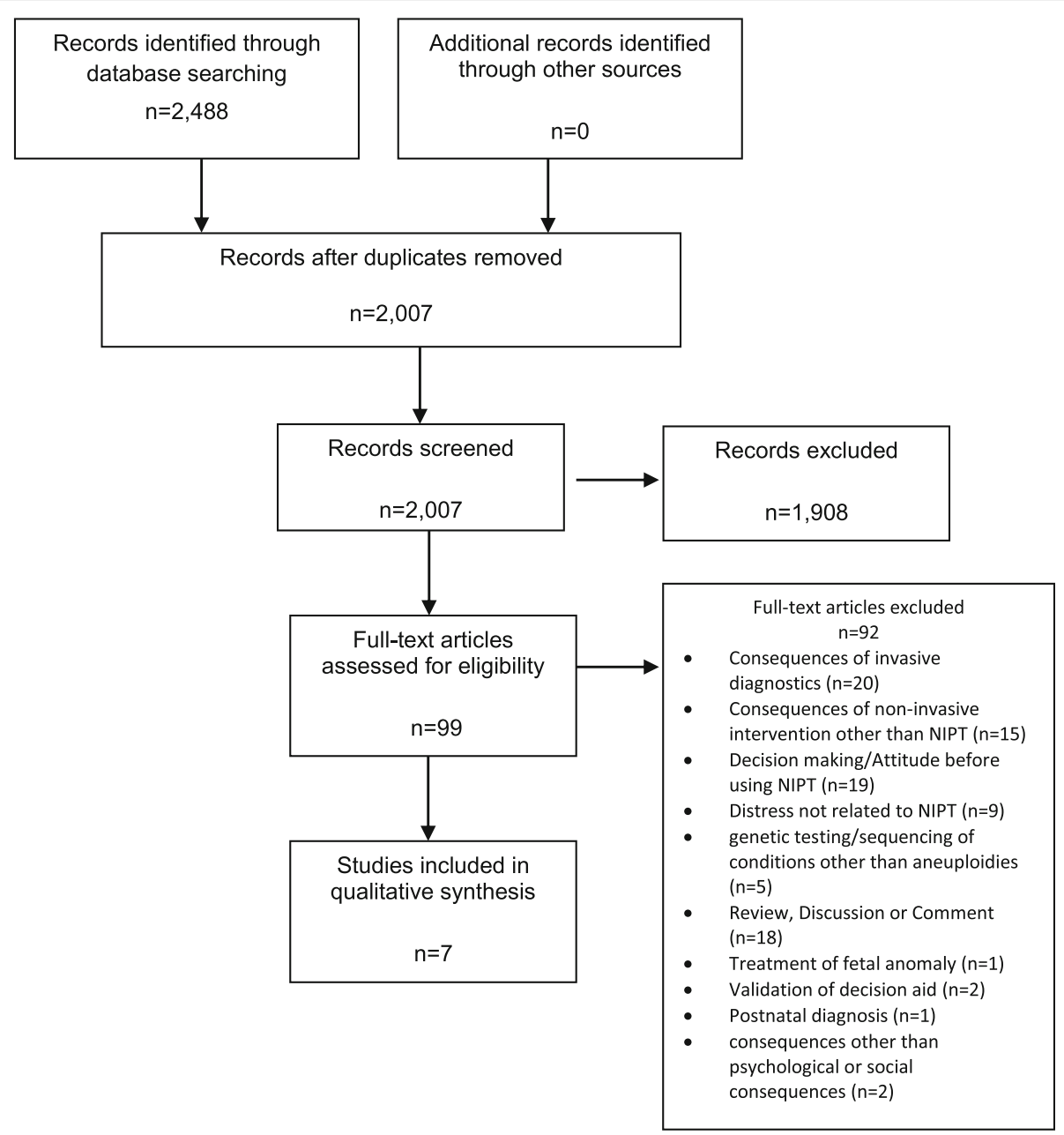

Fig. 1 PRISMA Flow Chart

Most studies recruited women with an elevated Down syndrome screening (DSS) risk (medium and/or high risk, cut-offs vary, range from $>1: 1000$ to $1: 1-125$ ) [20$22,24,25]$, two studies recruited from an unselected population regarding DSS $[19,23]$.

In all studies, psychological or social consequences of women who had NIPT were assessed (e.g. anxiety, distress after NIPT or experiences with NIPT); two studies also comprised women who had not undergone NIPT $[19,21]$. See below for a detailed description of the outcomes.

Takeda et al. only included women with negative NIPT results [23], in the study of Richmond et al. all women received negative NIPT results $(n=113$ (of 115) women received a negative result, $n=2$ women were excluded due to failed NIPT) [22]. Lewis et al., Lo et al., and van Schendel et al. included women with either negative or positive NIPT results [20, 21, 24]. Farrell et al. and Vanstone et al. did not report on NIPT results $[19,25]$.
All studies except one [21] reported limitations, for example, lack of control group (i.e. without NIPT), low response rates (i.e. to initial recruiting or second questionnaires), or origin of participating women from a selected community (i.e. older and highly educated).

\section{Description of the assessed outcomes \\ Anxiety}

Four studies assessed anxiety with the Spielberger State-Trait Anxiety Inventory (STAI or short form STAI-6) [20-22, 24].

In the studies of Lewis et al., Richmond et al., and van Schendel et al. women experienced a decrease in state anxiety from baseline to the time point after receiving NIPT results (reported by a decrease in STAI mean scores). Richmond et al. $(n=113)$ and van Schendel et al. $(n=656)$ report the decrease in state anxiety for women with negative NIPT results, the women in Lewis et al.'s study $(n=263)$ received either negative or positive NIPT results. 
Richmond et al. compared state anxiety in two subgroups of women: women with a high-risk combined first trimester screening (cFTS) result were significantly more anxious at baseline compared to women with a low-risk cFTS result; nevertheless, both groups experienced similar levels of state anxiety 1 week after receiving NIPT results.

The rate of women experiencing elevated anxiety (i.e. a STAI-6 score $\geq 50 / 80$ ) significantly decreased from baseline to the time point after receiving NIPT results in the studies of Lewis et al. $(n=263)$ and Lo et al. $(n=$ 254). Van Schendel et al. reported that the subgroup of women receiving positive NIPT results $(n=26)$ experienced high levels of anxiety after receiving those.

Van Schendel et al. $(n=656)$ assessed child-related anxiety with a subscale of the Pregnancy-Related Anxiety Questionnaire-Revised (PRAQ-R). Women who received negative test results experienced significantly lower levels of child-related anxiety after receiving negative test results compared to baseline. For more details, see Table 2 .

\section{Psychological distress}

One study assessed psychological distress with the Kessler Psychological Distress Scale (K6) after NIPT in a case-control setting [23]. All women in Takeda et al.'s study $(n=697)$ had received negative NIPT-results and experienced low psychological distress (i.e. low K6 scores) at baseline. The women who were assigned to the case group $(n=29)$ experienced psychological distress after giving birth (i.e. high post-partum K6 scores), the women in the control group $(n=668)$ did not experience psychological distress after giving birth (i.e. low post-partum K6 scores). Factors that contributed to psychological distress in women post-partum were for example low birth weight or primiparity. For more details, see Table 2.

\section{Decisional regret}

Two studies assessed decisional regret (i.e. distress or remorse) after women's decision for NIPT with the Decisional Regret Scale (DRS) [20, 21]. In the study of Lewis et al. $(n=263)$ decisional regret was very low among women after receiving (positive or negative) NIPT test results. In the study of Lo et al. $(n=223)$ decisional regret was low: among the $n=13$ women experiencing decisional regret, $n=12$ had received negative NIPT results. Women with insufficient knowledge about NIPT experienced decisional regret more commonly. For more details see Table 2 .

\section{Experiences with NIPT}

Van Schendel et al. assessed experiences with NIPT in questionnaires [24]. Either a group of women with only negative NIPT results or a group of women with negative or positive results were queried. Women with negative NIPT results $(n=656)$ mostly felt sufficiently reassured by the test result and were confident that the result was correct and that their child was not affected by a disorder. Some of the women with negative NIPT results $(n=16)$ would have preferred invasive testing over NIPT because of a shorter waiting time and more accurate results.

Of the women with either negative or positive NIPT results $(n=682)$, the majority had no regret about NIPT. About a third of those women would have preferred to receive results earlier; the reported mean waiting time of 15 days (range $5-32$ days) was considered too long by about two thirds of women. A waiting time of $\leq 10$ days would have been acceptable for most women. For more details, see Table 3 .

Vanstone et al. interviewed $n=38$ women with the aim of identifying their values about publicly funded NIPT to inform future formal policy making [25]. Here, we only considered statements that had clearly been made after NIPT. Due to anonymization, we cannot tell from how many different women the quotes originate. Waiting time for results was an aspect that was described as very stressful, especially for women who considered either confirmatory invasive testing or pregnancy termination, both of which are only available at a certain gestational age. The possibility of an inconclusive result was also stressful for some women, whereas they described a high confidence in negative NIPT results. For more details, see Table 4 .

Among the $n=58$ women who participated in the focus groups of Farrell et al., only $n=10$ had NIPT. Here again, we only considered statements that were clearly made after NIPT. One woman stated that the diagnostic accuracy of NIPT was sufficiently reassuring for her and that she almost considered it as confirmative. One woman reported that she had known the fetal sex of her unborn child 5 weeks earlier than would have been possible with ultrasound. This latter aspect was the only one we could find on social aspects among all the included studies. For more details, see Table 4.

\section{Discussion}

In this scoping review, we identified seven studies that investigated psychological and/or social consequences after NIPT [19-25].

The studies that evaluated anxiety [20-22, 24] (state, elevated, or child-related) assessed outcomes either in women who had all received positive NIPT results [24], or in women who all had received negative NIPT results $[22,24]$, or in a mixed group of women [20]. None of the studies had a control group without NIPT, nor were comparisons made between women who had positive 
NIPT results and women who had negative NIPT results. Considering all studies reporting on anxiety, we cannot know if the observed decrease in anxiety is related to NIPT (or the NIPT result). A recent study (not included) on $n=37$ women showed, that state anxiety levels (STAI) in pregnant women also decreased after ultrasound exams [26].

Similarly, in the two studies $[20,21]$ that found low levels of decisional regret after receiving NIPT results, the participating women had received either positive or negative results; no control group without NIPT was examined in the studies. Interestingly, among the $n=13$ women experiencing decisional regret in the study of Lo et al. [21], all but one had received negative NIPT results.

Psychological distress was assessed among women with negative NIPT findings in one study in a casecontrol setting [23], wherein cases were defined as having developed psychological distress after giving birth. The authors identified several factors like parity or the mode of conception as factors for psychological distress, but again, NIPT as a factor itself could not be identified as one of those factors due to study design (no control group without NIPT).

Three studies qualitatively assessed experiences with NIPT via questionnaires, interviews, or focus groups. In the study of Van Schendel et al. [24] subgroup analysis for women with only positive NIPT findings were not feasible, although aspects like reassurance or confidence in the test results would have been interesting for both subgroups of women, i.e. for women with positive or negative NIPT results. Quotes from women from interviews (Vanstone et al. [25]) or focus groups (Farrell et al. [19]) on the aspects of waiting time and accuracy of test results correspond to Van Schendel et al.'s findings from questionnaires: Waiting time was experienced as long and/or stressful, and women had a high confidence in negative NIPT results. Waiting times for other (invasive) prenatal tests are comparable; for example, results from amniocentesis are usually available after 3 weeks.

A social aspect that only Farrell et al. [19] reported on is the possibility of the early identification of fetal sex with NIPT. This might raise issues in societies where one sex is preferred over another and an early detection might enable earlier termination of pregnancies. For this reason in Germany, for example, the identification of fetal sex will only be communicated after week 12 postconception, when abortion without medical indication is not possible anymore [27].

We could not identify studies on the long-term psychological or social consequences of NIPT, such as decisional regret after several years. Because negative NIPT results usually do not entail further diagnostics, especially the long term psychological or social outcomes after positive NIPT results might be of interest. On an individual level, the psychological outcomes of women who receive a positive NIPT result and either chose to have or not to have confirmative invasive diagnostics could be interesting. Comparative studies on anxiety or levels of stress during pregnancy could elucidate those questions.

On population level, questions on the long term consequences of NIPT could be interesting, for example, whether the societal acceptance of children with fetal anomaly changes, or also if issues such as early abortions due to a not preferred sex of the fetus become acceptable.

Studies on psychological or social consequences of women's partners have not been found. Carlsson et al. interviewed expectant fathers of fetuses that were diagnosed with a congenital heart defect and found that fathers also experienced intense emotional shock and are at risk of not receiving adequate support, because they set their needs aside to support their partner [28].

Considering that NIPT was introduced 8 years ago, the number of included studies at this point appears to be relatively low. In comparison to the number of studies that were included in a Cochrane Review on the diagnostic test accuracy of NIPT $(n=65$ from 2007 to 2016) [1], the available data on psychological or social consequences of NIPT is considerably more scarce. Our findings support a statement of Bryant from 2014: "the effect of test characteristics and the social context in which they are offered has been one of the least researched topics in the psychology of screening" [29].

NIPT being a non-invasive test might remove the parent's fear of harming the fetus in an invasive procedure; however, the anxiety and distress that are often related to a diagnostic situation remain. Çakar et al., identified the fear of receiving bad news as a main factor why patients feel anxious before an invasive procedure. Moreover, they found that patients who had received information from doctors or nurses had lower anxiety levels compared to patients who had either received no information or information from friends and family [30]. The fact that NIPT is only available in a controlled medical environment (and not for sale on the internet) might help to assure good quality counseling and reduce patients' anxiety. Distress in non-invasive prenatal screening situations other than NIPT was found to be reduced by delivering information about testing correctly and thus helping patients to make informed decisions [31].

Good counseling is even more important for NIPT because parents might only be aware of the benefits 
of NIPT and might not anticipate the consequences. Because the positive predictive value of a test correlates with the prevalence of the disease in the population tested, the test accuracy is better in populations with a high risk [32]. If NIPT was offered routinely in obstetrical care (i.e. for women that are not at high risk of fetal aneuploidy), the rate of false positive results would increase. Hence, more women, who did not consider themselves to be at risk, would be confronted with false positive results and possibly experience psychological distress.

NIPT is being expanded beyond trisomy 21 and chromosome aneuploidies; screening for the fetal rhesus D status or monogenic diseases like thalassemia is already possible [33]. The future development of NIPT for a panel of relatively rare genetic disorders (i.e. that have a low prevalence in the general population) would similarly result in a higher rate of false positive results for women who are not at a high risk. Consequences might thus be further testing and increased anxiety, especially if knowledge about certain diseases and treatment options is little. Moreover, parents might not be aware of the fact that NIPT can only assess a small subset of anomalies and that a negative NIPT result does not give full certainty about the health of the fetus.

In our scoping review, we included a limited number of studies that assessed psychological and social outcomes with different methodologies and with women from different countries and cultural contexts. We assume that those results would also apply to populations comparable to the ones studied, and would thus also be applicable to Germany or other European countries.

\section{Conclusions}

More research on the psychological and social consequences is desirable, since NIPT might become a part of prenatal care in many countries. In 2019, for instance, the German Federal Joint Committee (Gemeinsamer Bundesausschuss, G-BA) will decide on the reimbursement of NIPT by statutory health insurance funds (Gesetzliche Krankenversicherung, GKV) in pregnancies with a high risk of anomalies. Of note, it is not planned to be used as a routine screening test.

It is important to make expecting parents aware of possible short- and long-term psychological and social consequences. The mapping of studies that analyze psychological and social consequences of NIPT is one step toward identifying research gaps and encouraging new research so that there will be a sound empirical basis that both physicians and parents can use to make fully informed decisions on the use of NIPT.

\section{Supplementary information}

Supplementary information accompanies this paper at https://doi.org/10. 1186/s12884-019-2518-x.

Additional file 1. Search strategies for the databases searched.

\begin{abstract}
Abbreviations
AMA: Advanced maternal age; cffDNA: Cell-free fetal DNA; cFTS: Combined first trimester screening; Cl: Confidence interval; COl: Conflicts of interest; DRS: Decisional Regret Scale; DSS: Down syndrome screening; FCT: Firsttrimester combined test; K6: Kessler psychological distress scale; n: Number; NIPT: Non-invasive prenatal testing; ORCID: Open researcher and contributor ID; p: p-value; PRAQ-R: Pregnancy-related anxiety questionnaire-revised; Q1, Q2: Questionnaire 1, questionnaire 2; SD: Standard deviation;

STAI: Spielberger State-Trait Anxiety Inventory; vs: Versus; ys: Years
\end{abstract}

\section{Acknowledgements}

We thank our information specialist Edith Motschall (EM), Institute of Medical Biometry and Statistics (IMBI), University of Freiburg, for her help with the search strategy.

\section{Authors' contributions}

$\mathrm{VL}, \mathrm{BL}$ and $\mathrm{JM}$ developed the concept; $\mathrm{VL}$ and $\mathrm{DA}$ screened references and extracted data; $V L$ drafted the manuscript; DA, BL and JM critically reviewed and commented on the manuscript. All authors have read and approved the manuscript.

\section{Funding}

The project was funded by the German Federal Ministry of Education and Research (Bundesministerium für Bildung und Forschung, BMBF,

Förderkennzeichen 01GP1771B). The article processing charge was funded by the German Research Foundation (DFG) and the University of Freiburg in the funding program Open Access Publishing. The funders did not play a role in the design of this study, or in the collection, analysis, or interpretation of the data, or in the writing of the manuscript.

\section{Availability of data and materials}

The dataset used and analyzed during the current study is available from the corresponding author on reasonable request.

Ethics approval and consent to participate

Not applicable.

Consent for publication

Not applicable.

\section{Competing interests}

VL and JM work for Cochrane Germany.

\section{Author details}

${ }^{1}$ Institute for Evidence in Medicine, Medical Center - University of Freiburg, Faculty of Medicine, University of Freiburg, Breisacherstr. 153, 79110 Freiburg, Germany. ${ }^{2}$ Clinical Trial Unit, Medical Center - University of Freiburg, Faculty of Medicine, University of Freiburg, Elsässer Str. 2, 79110 Freiburg, Germany.

Received: 23 May 2019 Accepted: 20 September 2019

Published online: 28 October 2019

\section{References}

1. Badeau M, Lindsay C, Blais J, Nshimyumukiza L, Takwoingi Y, Langlois S, et al. Genomics-based non-invasive prenatal testing for detection of fetal chromosomal aneuploidy in pregnant women. Cochrane Database Syst Rev. 2017;11(11):CD011767.

2. Ostermaier KK. Down syndrome: Clinical features and diagnosis. In: Drutz JE, Firth HV, TePas E, editors. UpToDate: UpToDate, Post TW (Ed), UpToDate. Waltham. Accessed Feb 04 2019; 2018.

3. Levis DM, Harris S, Whitehead N, Moultrie R, Duwe K, Rasmussen SA. Women's knowledge, attitudes, and beliefs about Down syndrome: a qualitative research study. Am J Med Genet A. 2012;158A(6):1355-62. 
4. Messerlian GM, Farina A, Palomaki GE. First-trimester combined test and integrated tests for screening for Down syndrome and trisomy 18. In: Louise Wilkins-Haug M, Vanessa A, Barss M, editors. UpToDate: UpToDate, Post TW (Ed), UpToDate. Waltham. Accessed Feb 04 2019; 2018.

5. Fretts RC. Effects of advanced maternal age on pregnancy: UpToDate, Post TW (Ed), UpToDate. Waltham. Accessed Feb 04 2019; 2019.

6. Green J, Hewison J, Bekker H, Bryant L, H. C. Psychosocial aspects of genetic screening of pregnant women and newborns: a systematic review. Health Technology Assessment. 2004;8(33):1-124.

7. Bryant LD. Biopsychosocial factors in prenatal screening and diagnosis for fetal anomaly. In: Edozien LC, O'Brien PMS, Edozien LC, O'Brien PMS, editors. Biopsychosocial factors in obstetrics and gynaecology. New York: Cambridge University Press; 2017. p. 237-44

8. Hodgson J, McClaren BJ. Parental experiences after prenatal diagnosis of fetal abnormality. Semin Fetal Neonatal Med. 2018;23(2):150-4.

9. Coussons-Read ME. Effects of prenatal stress on pregnancy and human development: mechanisms and pathways. Obstet Med. 2013, 6(2):52-7

10. Griffin B, Edwards S, Chitty LS, Lewis C. Clinical, social and ethical issues associated with non-invasive prenatal testing for aneuploidy. J Psychosom Obstet Gynaecol. 2018;39(1):11-8.

11. Lewis C, Choudhury M, Chitty LS. 'Hope for safe prenatal gene tests'. A content analysis of how the UK press media are reporting advances in noninvasive prenatal testing. Prenat Diagn. 2015;35(5):420-7.

12. Colquhoun HL, Levac D, O'Brien KK, Straus $S$, Tricco AC, Perrier $L$, et al. Scoping reviews: time for clarity in definition, methods, and reporting. J Clin Epidemiol. 2014;67:1291-4.

13. Tricco AC, Lillie E, Zarin W, O'Brien K, Colquhoun $\mathrm{H}$, Kastner M, et al. A scoping review on the conduct and reporting of scoping reviews. BMC Med Res Methodol. 2016;16:15.

14. Arksey H, O'Malley L. Scoping studies: towards a methodological framework. Int J Soc Res Methodol. 2005:8:19-32.

15. Levac D, Colquhoun H, O'Brien KK. Scoping studies: advancing the methodology. Implementation Sci. 2010;5:69.

16. Allyse M, Minear MA, Berson E, Sridhar S, Rote M, Hung A, et al. Noninvasive prenatal testing: a review of international implementation and challenges. Int J Womens Health. 2015;7:113-26.

17. Bramer WM, Giustini D, de Jonge GB, Holland L, Bekhuis T. De-duplication of database search results for systematic reviews in EndNote. J Med Libr Assoc. 2016;104(3):240-3.

18. Covidence. Covidence systematic review software: Veritas Health Innovation, Melbourne, Australia; 2019. Available from: www. covidence.org. Accessed 11 Feb 2019.

19. Farrell RM, Mercer MB, Agatisa PK, Smith MB, Philipson E. It's more than a blood test: Patients' perspectives on noninvasive prenatal testing. J Clin Med. 2014;3(2):614-31.

20. Lewis $C$, Hill M, Chitty LS. Women's experiences and preferences for service delivery of non-invasive prenatal testing for aneuploidy in a public health setting: a mixed methods study. PLoS One. 2016:11(4):e0153147.

21. Lo TK, Chan KY, Kan AS, So PL, Kong CW, Mak SL, et al. Decision outcomes in women offered noninvasive prenatal test (NIPT) for positive down screening results. J Matern Fetal Neonatal Med. 2019;32(2):348-50 Epub 2017 Sep 19.

22. Richmond Z, Fleischer R, Chopra M, Pinner J, D'Souza M, Fridgant Y, et al. The impact of non-invasive prenatal testing on anxiety in women considered at high or low risk for aneuploidy after combined first trimester screening. Prenat Diagn. 2017;37(10):975-82.

23. Takeda E, Suzumori N, Ebara T, Yotsumoto J, Kumagai K, Oseto K, et al. Psychological distress in post-partum women after non-invasive prenatal testing (NIPT) in Japan. J Obstet Gynaecol Res. 2018;44(1):35-42.

24. van Schendel RV, Page-Christiaens G, Beulen L, Bilardo CM, de Boer MA, Coumans $A B C$, et al. Women's experience with non-invasive prenatal testing and emotional well-being and satisfaction after test-results. J Genet Couns. 2017;26(6):1348-56.

25. Vanstone M, Yacoub K, Giacomini M, Hulan D, McDonald S. Women's experiences of publicly funded non-invasive prenatal testing in Ontario, Canada: considerations for health technology policy-making. Qual Health Res. 2015;25(8):1069-84.

26. Simo S, Zuniga L, Izquierdo MT, Rodrigo MF. Effects of ultrasound on anxiety and psychosocial adaptation to pregnancy. Arch Womens Ment Health. 2019;22(4):511-8

27. Gesetz über genetische Untersuchungen bei Menschen (Gendiagnostikgesetz - GenDG), Abs 2: Genetische Untersuchungen zu medizinischen Zwecken, § 15 Vorgeburtliche genetische Untersuchungen, 01.02.2010.

28. Carlsson T, Mattsson E. Emotional and cognitive experiences during the time of diagnosis and decision-making following a prenatal diagnosis: a qualitative study of males presented with congenital heart defect in the fetus carried by their pregnant partner. BMC Pregnancy Childbirth. 2018;18(1):26

29. Bryant L. Non-invasive prenatal testing for Down's syndrome: psychologically speaking, what else do we need to know? J Reprod Infant Psychol. 2014;32(1):1-4.

30. Cakar M, Tari Kasnakoglu B, Okem ZG, Okuducu U, Beksac MS. The effect of different information sources on the anxiety level of pregnant women who underwent invasive prenatal testing. J Matern Fetal Neonatal Med. 2016; 29(23):3843-7.

31. Skutilova V. Knowledge, attitudes and decision-making in Czech women with atypical results of prenatal screening tests for the most common chromosomal and morphological congenital defects in the fetus: selected questionnaire results. Biomed Pap Med Fac Univ Palacky Olomouc Czech Repub. 2015;159(1):156-62

32. Skrzypek H, Hui L. Noninvasive prenatal testing for fetal aneuploidy and single gene disorders. Best Pract Res Clin Obstet Gynaecol. 2017;42:26-38.

33. Breveglieri G, D'Aversa E, Finotti A, Borgatti M. Non-invasive prenatal testing using fetal DNA. Molecular Diagnosis Ther. 2019;23(2):291-9.

\section{Publisher's Note}

Springer Nature remains neutral with regard to jurisdictional claims in published maps and institutional affiliations.
Ready to submit your research? Choose BMC and benefit from:

- fast, convenient online submission

- thorough peer review by experienced researchers in your field

- rapid publication on acceptance

- support for research data, including large and complex data types

- gold Open Access which fosters wider collaboration and increased citations

- maximum visibility for your research: over $100 \mathrm{M}$ website views per year

At $\mathrm{BMC}$, research is always in progress.

Learn more biomedcentral.com/submissions 